\title{
Does Rifaximin Improve EEG and VEP in Egyptian Cirrhotic Patients with Minimal Hepatic Encephalopathy?
}

\author{
Amr Mohamed Abdelfattah', Al-Amir Bassiouny Mohamed², Gharib Fawi'2, Badr Ragab'2, \\ Hassan M. Elnady ${ }^{2}$, Mohamed Malak ${ }^{3}$
}

${ }^{1}$ Department of Gastroentrology and Tropical Medicine, Sohag University, Sohag, Egypt

${ }^{2}$ Department of Neurology and Psychological Medicine, Sohag University, Sohag, Egypt

${ }^{3}$ Department of Internal Medicine, Sohag University, Sohag, Egypt

Email: amrmoh_80@yahoo.com

How to cite this paper: Abdelfattah, A.M., Mohamed, A.-A.B., Fawi, G., Ragab, B., Elnady, H.M. and Malak, M. (2018) Does Rifaximin Improve EEG and VEP in Egyptian Cirrhotic Patients with Minimal Hepatic Encephalopathy? Open Journal of Gastroenterology, 8, 362-376.

https://doi.org/10.4236/ojgas.2018.810038

Received: August 9, 2018

Accepted: October 21, 2018

Published: October 24, 2018

Copyright $\odot 2018$ by authors and Scientific Research Publishing Inc. This work is licensed under the Creative Commons Attribution International License (CC BY 4.0).

http://creativecommons.org/licenses/by/4.0/

(C) (i) Open Access

\begin{abstract}
Background: Minimal hepatic Encephalopathy (MHE) is defined as HE without symptoms on clinical/neurological examination, but with deficits in some cognitive areas that can only be measured by neuropsychometric testing. However, numerous studies have shown that, although the neurological symptoms are slight, affected patients are markedly impaired in their quality of life and ability to work. Various treatment modalities that have been shown to reverse MHE include lactulose/lactitol, probiotics/synbiotics, L-carnitine but rifaximin has shown a general trend toward better efficacy and better tolerability in patients with overt hepatic encephalopathy (OHE). Objective: Our objective is to assess the diagnostic role of minimental state examination (MMSE), electroencephalography (EEG) and visual evoked potential (VEP) in detection of MHE and to evaluate the efficacy of rifaximin in improving EEG and VEP in patients with MHE. Patients and Methods: Sixty cirrhotic patients were enrolled in the study depending on clinical evidence of stigmata of chronic liver disease, laboratory investigations including liver function tests, ultrasonographic features of liver cirrhosis and with no evidence of overt hepatic encephalopathy. Diagnois of MHE was made depending on minimental state examination (MMSE) and neurophysiological tools including EEG and VEP. A control group of sixty healthy volunteers with age and sex matched were included. The patient group received Rifaximin $550 \mathrm{mg}$ twice daily for 8 weeks then follow up EEG and VEP studies were done. Results: MHE was detected in $36.7 \%, 48.3 \%, 51.7 \%$ of our series based on MMSE, EEG and VEP respectively. Child Pouph A, B, C was found in 51.7\%, 35\%, $13.3 \%$ respectively. Rifaximin was well tolerated. At the end of treatment,
\end{abstract}


EEG and VEP studies were done which showed signficant changes between pre and post treatment results $(\mathrm{P}$ value $=0.03,0.001,<0.001)$. Conclusion: MMSE as well as EEG and VEP were reasonable diagnostic tools for early detection of MHE particularly in countries with low level of education. Rifaximin significantly improves both EEG and VEP in cirrhotic patients with MHE.

\section{Keywords}

MHE, EEG, VEP, Rifaximin

\section{Introduction}

Minimal hepatic Encephalopathy (MHE) is defined as HE without symptoms on clinical/neurological examination, but with deficits in some cognitive areas that can only be measured by neuropsychometric testing [1].

MHE has a high frequency among patients with liver cirrhosis (22\% - 74\%) and also occurs in patients with portosystemic shunt [2] but the true frequency of patients with MHE is unknown, because MHE often remains undiagnosed due to the lack of evident symptoms and standardized clinical criteria and diagnosis rest mainly on careful patient history and physical examination, normal mental status examination, demonstration of abnormalities in cognition and/or neurophysiological function, and exclusion of concomitant neurological disorders [3] [4].

However, numerous studies have shown that, although the neurological symptoms are slight, affected patients are markedly impaired in their quality of life and ability to work [5]. Various tools have been evaluated for the diagnosis of MHE including neuropsychological tests, neurophysiological tests as auditory brain stem response, P300 event, regional cerebral blood flow changes [6].

Various treatment modalities that have been shown to reverse MHE include lactulose/lactitol, probiotics/synbiotics, L-carnitine, branched-chain amino acids [7]. Rifaximin is a non-absorbable, gut-specifi c antibiotic. Compared with lactulose or neomycin, rifaximin has shown a general trend toward better efficacy and better tolerability in patients with OHE [8].

A proportion of patients with cirrhosis exhibit disturbances in orientation, attention, constructional praxia, psychomotor speed and executive function, which are collectively termed hepatic encephalopathy (HE. [9] [10] [11] [12].

Mental State Examination (MMSE) covers such cognitive domains [13], at least tosome extent, and has been utilized also in this patient population [14] [15].

The use of MMSE is considered especially in low educational level countries and the milder forms of clinically overt HE pose a considerable diagnostic problem, and the criteria currently in use-the so-called West Haven criteria [16] have been criticized and deemed to be far too operator-dependent [13].

Thabut et al. reported that the validated for the diagnosis of cognitive impairment (Mini-MMSE and Montreal Cognitive Assessment) were superior than 
psychometric hepatic encephalopathy scor (PHES) in detection of MHE and so PHES require a validation in each country before assessing performances of this score in apathological setting [17].

The neurophysiological investigation of hepatic encephalopathy (HE) is generally performed by the electroencephalogram (EEG) and the evoked potentials (EPs). The EEG reflects the post-synaptic activity of pools of the large pyramidal cells of the fourth layer of the braincortex and is extremely sensitive to the influence of toxic, pharmacological and metabolic factors. Evoked potentials reflect the electric summation of neuronal activity related to sensory, motor stimuli or to cognitive processes. Changes in the latency of sensory and motor EPs reflect changes in transmission time and changes in EPs amplitude reflect changes in the synchronization and in the amount of the activated neurons [18].

The present case control study was conducted to assess the efficacy of rifaximin on EEG and VEP as neuropgysiological diagnostic tools of MHE.

\section{Patients and Methods}

\subsection{Patients}

The present case control study was carried out on patients with liver cirrhosis and healthy individuals to inestigate the role of Rifaximin in MHE and to early detect MHE. This study was carried out at the Department of Neurology jointly with Department of Gastroenterology and Tropical Medicine at Sohag University Hospitals Egypt between November 2017 and July 2018. The patient group received Rifaximin $550 \mathrm{mg}$ twice daily for 8 weeks then follow up EEG and VEP studies were done; a group of age and sex matched healthy sixty volunteers as a control group.

\subsection{Inclusion Criteria}

The study included included 60 cirrhotic patients depending on clinical evidence of stigmata of chronic liver disease (e.g. jaundice, ascites, palmar erythema, spider naevi, etc.) and ultrasonographic features of liver cirrhosis (e.g. coarse echo texture, shrunken liver, etc.).

\subsection{Exclusion Criteria}

Patients with any neurological disease affect conscious level including recent head trauma and patients taking benzodiazepines or antidepressants were excluded, also patients with visual deficiency were excluded.

Patients with overt hepatic encephalopathy, history of alcohol intake, drug abuse, drug intake as sedatives, diabetes mellitus, chronic renal failure, transjugular intrahepatic porto-systemic shunt were excluded from the study in order to avoid coexistent neuropathy or other brain dysfunction.

The control group consisted of healthy individuals which were selected to match with the patient group with respect to age, gender, education and sociodemographic characteristics. 
Each patient included in the study was subjected to:

1) Complete history taking and physical examination.

The clinical assessment included a full neurological examination and a clinical grading of the neuropsychiatric abnormalities.

Each patient's mental status was assessed by an experienced physician. The assessment included detailed and comprehensive medical history, full neurological examination.

2) Laboratory investigations:

Aspartate aminotransferase (AST), Alanine aminotransferase (ALT), serum alkaline phosphatase, serum albumin, prothrombin time and concentration, total \& differential bilirubin, hepatitis markers for HBV and HCV, blood sugar, Haemoglobin level $(\mathrm{Hb})$, serum creatinine.

\section{Assessment of the Severity of Liver Disease}

\subsection{Child-Pugh Grading System}

The functional severity of liver disease was assessed using the Child-Pugh grading system [19] (Table 1).

Child-pugh score: [19].

\subsection{Abdominal Ultrasonography}

To evaluate liver size, echogenicity and any focal lesion, portal vein diameter, spleen, portosystemic collaterals, and detect ascites.

\section{Neuropsychiatric Assessment}

All patients underwent MMSE, EEG and VEP recording.

\subsection{MMSE}

This was performed by an experienced neuropsychologist in the morning, after breakfast, in a quiet well-lit room, in standardized conditions.

Table 1. Calculation of the Child-Pugh Score (CPS).

\begin{tabular}{|c|c|c|c|}
\hline & 1 point & 2 points & 3 points \\
\hline Serum bilirubin imol $\backslash \mathrm{L}$ & $<34$ & $35-50$ & $>51$ \\
\hline Serum albumin gldl & $>3.5$ & $3.0-3.5$ & $<3.0$ \\
\hline Prothrombin time & $0-4$ & $4-6$ & $>6$ \\
\hline INR & $<1.7$ & $1.7-2.3$ & $>2.3$ \\
\hline ascites & None & $\begin{array}{l}\text { Slight medically } \\
\text { controlled }\end{array}$ & $\begin{array}{l}\text { Moderate-Severe, } \\
\text { poorly controlled }\end{array}$ \\
\hline Encephalopathy & None & Stage 1 - 2 & Stage 3 - 4 \\
\hline $\begin{array}{c}\text { Total score combine } \\
\text { scores from all } 5 \text { factors } \\
\text { noted above }\end{array}$ & $5-7$ & $7-9$ & $10-15$ \\
\hline Child-Pugh Score (CPS): & A & B & $\mathrm{C}$ \\
\hline
\end{tabular}


MMSE: The test includes 11 items, divided into two sections. The first section requires verbal responses to questions assessing orientation, memory and attention (orientation to place/time, repetition, calculation, recall); the second section tests the ability to name objects (denomination), follow verbal and written commands (complex verbal/written comprehension), writea sentence spontaneously, copy a drawing and praxia (writing, copying a complex geometrical drawing).

Eachitem is attributed a different set of points, ranging from 1 to 5 . The total score ranges from 0 to 30, and scores below 24 are considered abnormal 1, 2 [13] [20].

The participants were subdivided according to their educational level into 4 groups: illiterate, lower educational level (1 - 5 years), middle educational level (6 - 11 years) and higher educational level ( $\geq 12$ years) [21]. Lourenço and Veras used the cutoff points, 18 for illiterate individuals and 24 for individuals with some educational level [22] [23].

\subsection{EEG Recordings}

EEGs were recorded with a 21-electrode EEG cap, eyes closed, in a condition of relaxed wakefulness. Electrodes were placed according to the International 10 20 system; the ground and reference electrode were $\mathrm{Fpz}$ and $\mathrm{Oz}$, respectively; impedance was kept below $5 \mathrm{KU}$ (Nihon Kohden, Japan equipment).

EEG recording was performed for a total time of $10 \mathrm{~min}$.

Patients were stratified according to their EEG features assessed according to modified Parsons-Simith classification [24] [25] (Table 2).

Table 2. Modified parsons-simith classification [25].

\begin{tabular}{|c|c|c|}
\hline & Score & Description \\
\hline Normal EEG & 0 & $\begin{array}{l}\text { Well-structured EEG with stable and symmetrical posterior basic } \\
\text { rhythm }>8 \mathrm{~Hz} \text { and }<13 \mathrm{~Hz} \text { dominant in the posterior regions. } \\
\text { Such activity has medium amplitude }(30-50 \mu \mathrm{V}) \text { and is reactive } \\
\text { to eye opening. No slow activities or epileptic pattern are present }\end{array}$ \\
\hline Normal-limit EEG & 1 & $\begin{array}{c}\text { Instable or suppressed alpha rhythm frequently replaced by high } \\
\text { prevalence of diffuse beta rhythm (corresponding to } \\
\text { grade A of Parsons-Simith's classification) }\end{array}$ \\
\hline $\begin{array}{c}\text { Mild signs of } \\
\text { encephalopathy: }\end{array}$ & 2 & $\begin{array}{l}\text { Low frequency alpha rhythm }(8 \mathrm{~Hz}) \text { disturbed by random } \\
\text { waves in the theta range over both hemispheres } \\
\text { (corresponding to grade B of Parsons-Simith's classification) }\end{array}$ \\
\hline $\begin{array}{l}\text { Distinctive features of } \\
\text { encephalopathy: }\end{array}$ & 3 & $\begin{array}{l}\text { Background activity in the theta range, diffused over } \\
\text { both hemispheres. Random appearance of high waves } \\
\text { in the delta range (roughly corresponding to } \\
\text { grade C of Parsons-Simith's classification) }\end{array}$ \\
\hline $\begin{array}{l}\text { Signs of severe } \\
\text { encephalopathy: }\end{array}$ & 4 & $\begin{array}{l}\text { Severe disorganization of EEG activity without any normal } \\
\text { element. Diffuse asynchronous theta and delta waves over } \\
\text { both hemispheres with or without triphasic waves (roughly } \\
\text { corresponding to grades D-E of Parsons-Simith's classification) }\end{array}$ \\
\hline
\end{tabular}




\section{3. c-VEP}

1) VEP recordings: VEP was recorded with a PC based, 4 channel, Nihon kohden machine and standard silver-silver chloride disc electrodes. A one channel montage was used for recording the VEP. The scalp electrodes were placed relative to bony landmarks, in proportion to the size of the head, according to the International 10/20 system [26]. The active electrode was placed at $\mathrm{Oz}$ which is the highest point of the occiput, lies over the visual cortex. The reference and ground electrodes were put at $\mathrm{Fz}$ and $\mathrm{Cz}$ (vertex), respectively. The recording was done in a dark room with quiet surroundings.

2) VEP stimulation: was done with a checkerboard pattern generated on the monitor using the software installed, which consisted of black and white checks whose phase was reversed (black to white and white to black) at a fixed rate of two reversals per second. The subject was seated at a fixed distance of $100 \mathrm{~cm}$ from the screen and was asked to fixate at the center of the screen. Monocular stimulation was given to both the eyes separately. A sweep length of $250 \mathrm{~ms}$ was done, and more than 100 responses were averaged. An amplification range of 20,000 to $1,00,000$ was used. To ensure reproducibility, the waveform was recorded twice. The electrode impedance was kept less than $5 \mathrm{~K} \Omega$.

The VEP parameters recorded were latencies to N70, P100 and N155 waves, and peak to peak amplitude of P100 wave. Tandon and Sharma reported the normal P100 latency of $95.37 \pm 6.85 \mathrm{msec}$ for males and $91.07 \pm 49 \mathrm{msec}$ for females [27].

The study was approved by the Ethics Committee on Research Involving $\mathrm{Hu}$ man Subjects at University of Sohag. All individuals invited were informed in detail about the investigation and voluntarily signed the Informed Consent Form with respect to patient's confidentiality.

\section{Statistics}

Data was analyzed using STATA intercooled version 12.1. Quantitative data was represented as mean, standard deviation, median and range. Data was analyzed using student t-test to compare means of two groups. When the data were not normally distributed Mann-Whitney test was used. Qualitative data were presented as number and percentage and compared using either Chi square test or fisher exact test. Either Pearson's or Spearman correlation analyses were used to measure the correlations among different variables. Graphs were produced by using Excel or STATA program. P value was considered significant if it was less than 0.05 .

\section{Results}

The current study included 60 cirrhotic patients (28 male) with mean age $47.5 \pm$ 6.8 years and 60 age and sex matched healthy volunteers (31 male) with mean age $42.5 \pm 5.7$.

Baseline characteristics of cirrhotic patients were shown in Table 3. 
Table 3. Baseline characteristics of cirrhotic patients.

\begin{tabular}{|c|c|c|}
\hline & Frequency & Percent \\
\hline Age (mean \pm SD) & $47.5 \pm 6.8$ & \\
\hline \multicolumn{3}{|l|}{ Sex } \\
\hline Male & 28 & $46.7 \%$ \\
\hline Female & 32 & $53.3 \%$ \\
\hline \multicolumn{3}{|l|}{ Educational level } \\
\hline Illeterate & 34 & $56.7 \%$ \\
\hline Primary school & 8 & $13.3 \%$ \\
\hline Middle school & 16 & $26.7 \%$ \\
\hline High school & 2 & $3.3 \%$ \\
\hline \multicolumn{3}{|l|}{ Minimental state examination } \\
\hline Normal & 38 & $63.3 \%$ \\
\hline Cognitive impairment & 22 & $36.7 \%$ \\
\hline MMSE $($ mean \pm SD) & $22.19 \pm 3.772$ & \\
\hline \multicolumn{3}{|l|}{ EEG } \\
\hline Normal (grade 1 - 2) & 31 & $51.7 \%$ \\
\hline Theta slowing (grade 3 ) & 10 & $16.7 \%$ \\
\hline Delta slowing (grade 4) & 12 & $20.0 \%$ \\
\hline Triphasic wave (grade 5) & 7 & $11.7 \%$ \\
\hline \multicolumn{3}{|l|}{ P100 latency } \\
\hline P100 latency right eye (mean \pm SD) & $122.3 \pm 29.6$ & \\
\hline P100 latency left eye (mean \pm SD) & $121.25 \pm 25.5$ & \\
\hline Abnormal P100 latency & $31(51.7 \%)$ & \\
\hline \multicolumn{3}{|l|}{ Child Pouph score } \\
\hline A & 31 & $51.7 \%$ \\
\hline B & 21 & $35.0 \%$ \\
\hline $\mathrm{C}$ & 8 & $13.3 \%$ \\
\hline \multicolumn{3}{|l|}{ Minimal hepatic encephalopathy } \\
\hline MHE diagnosed by MMSE & $22(36.7 \%)$ & \\
\hline MHE diagnosed by EEG & $29(48.3 \%$ & \\
\hline MHE diagnosed by VEP & $31(51.7 \%)$ & \\
\hline
\end{tabular}

Table 4 showed laboratory and neurophysiological characteristics of cirrhotic patients in relation to Child-Pugh grading system.

There was significant difference between the two groups as regard EEG and VEP as shown in Table 5.

Patients with MHE received Rifaximin $550 \mathrm{mg}$ twice daily for 8 weeks and follow up EEG changes and VEP P100 was done post treatment and Table 6, Figure 1 and Figure 2 showed significant changes in the EEG and VEP results $(\mathrm{P}$ value $=0.03,0.0001,0.0008)$ after administration of rifaximin . 
Table 4. Laboratory and neurophysiological characteristics of cirrhotic patients in relation to Child-Pugh grading system.

\begin{tabular}{|c|c|c|c|c|}
\hline & $\begin{array}{l}\text { Child-Pugh A } \\
\qquad \mathrm{N}=31\end{array}$ & $\begin{array}{l}\text { Child-Pugh B } \\
\qquad \mathrm{N}=21\end{array}$ & $\begin{array}{l}\text { Child-Pugh C } \\
\qquad \mathrm{N}=\mathbf{8}\end{array}$ & P-value \\
\hline Age (Years) & $48.7 \pm 7.9$ & $46.9 \pm 5.6$ & $44.5 \pm 3.8$ & 0.261 \\
\hline $\begin{array}{l}\text { Serum creatinine } \\
(\mathrm{mg} / \mathrm{dl})\end{array}$ & $1.1 \pm 0.4$ & $1.00 \pm 0.316$ & $1.00 \pm 0.000$ & 0.266 \\
\hline RBCs (million/ $/$ l) & $4.2 \pm 0.7$ & $4.1 \pm 0.8$ & $3.75 \pm 0.4$ & 0.202 \\
\hline $\mathrm{HGB}(\mathrm{gm} / \mathrm{dl})$ & $8.5 \pm 2.2$ & $9.5 \pm 2$ & $8.88 \pm 1.126$ & 0.245 \\
\hline WBCS (cells/ $\mu \mathrm{l})$ & $9.9 \pm 4.1$ & $9.1 \pm 2.8$ & $10.5 \pm 2.9$ & 0.56 \\
\hline Platelets $($ cells $/ \mu \mathrm{l})$ & $242.6 \pm 80.6$ & $244.4 \pm 99.1$ & $278.6 \pm 99.4$ & 0.58 \\
\hline MMSE & & & & 0.006 \\
\hline Mean \pm SD & $22.19 \pm 3.7$ & $21.33 \pm 3.6$ & $18.22 \pm 2.2$ & \\
\hline Normal & $22(71.0 \%)$ & $15(71.4 \%)$ & $1(12.5 \%)$ & \\
\hline Abnormal & $9(29.0 \%)$ & $6(28.6 \%)$ & $7(87.5 \%)$ & \\
\hline EEG & & & & $<0.001$ \\
\hline Normal (grade 0 - 1) & $22(71.0 \%)$ & $8(38.1 \%)$ & $1(12.5 \%)$ & \\
\hline theta slowing (grade 2) & $7(22.6 \%)$ & $2(9.5 \%)$ & $1(12.5 \%)$ & \\
\hline delta slowing (grade 3) & $2(6.5 \%)$ & $8(38.1 \%)$ & $2(25.0 \%)$ & \\
\hline triphasic wave (grade 4) & $0(0.0 \%)$ & $3(14.3 \%)$ & $4(50.0 \%)$ & \\
\hline \multicolumn{5}{|l|}{ P100 latency } \\
\hline normal & $23(74.2 \%)$ & $6(28.6 \%)$ & $0(0 \%)$ & $<0.001$ \\
\hline abnormal & $8(25.8 \%)$ & $15(71.4 \%)$ & $8(100.0 \%)$ & \\
\hline P100 latency right eye & $110.39 \pm 24.981$ & $135.10 \pm 31.010$ & $143.20 \pm 17.355$ & 0.002 \\
\hline P100 latency left eye & $109.87 \pm 20.142$ & $132.81 \pm 26.754$ & $143.20 \pm 14.704$ & $<001$ \\
\hline
\end{tabular}

Table 5. Comparison between patient and control groups as regard EEG and VEP.

\begin{tabular}{|c|c|c|c|}
\hline Variable & $\begin{array}{l}\text { Patient group } \\
\qquad N=60\end{array}$ & $\begin{array}{l}\text { Control group } \\
\qquad \mathrm{N}=60\end{array}$ & $P$ value \\
\hline EEG & & & 0.002 \\
\hline Normal & $31(51.6 \%)$ & $53(88.3 \%)$ & \\
\hline Theta slowing & $11(18.3 \%)$ & $7(11.7 \%)$ & \\
\hline Delta slowing & $12(20 \%)$ & $0(0 \%)$ & \\
\hline Triphasic wave & $7(11.6 \%)$ & $0(0 \%)$ & \\
\hline \multicolumn{4}{|c|}{ VEP P100 latency right eye } \\
\hline Mean \pm SD & $123.22 \pm 31.3$ & $99.37 \pm 3.9$ & $<0.0001$ \\
\hline Median (range) & $106(80-198)$ & $100(90-111)$ & \\
\hline \multicolumn{4}{|c|}{ VEP P100 latency left eye } \\
\hline Mean \pm SD & $120.8 \pm 26.7$ & $98.5 \pm 3.40$ & $<0.0001$ \\
\hline Median (range) & $105(88-171)$ & $99(90-105)$ & \\
\hline MMSE & $21.3 \pm 3.7$ & $25.8 \pm 2.9$ & 0.001 \\
\hline
\end{tabular}


Table 6. EEG and VEP results before and after rifaximin.

\begin{tabular}{cccc}
\hline Variable & Before rifaximin & After rifaximin & P value \\
\hline EEG & & & \\
Normal & $31(51.6 \%)$ & $47(78.33 \%)$ & 0.03 \\
Abnormal & $29(48.4 \%)$ & $13(21.67 \%)$ & \\
VEP P100 latency right eye & & & \\
Mean \pm SD & $123.22 \pm 31.35$ & $110.15 \pm 23.59$ & \\
Median (range) & $106(80-198)$ & $100.5(90-177)$ & 0.001 \\
VEP P100 latency left eye & & & \\
Mean \pm SD & $120.8 \pm 26.73$ & $110.28 \pm 23.74$ & \\
Median (range) & $105(88-171)$ & $100(90-187)$ & $<0.001$ \\
\hline
\end{tabular}

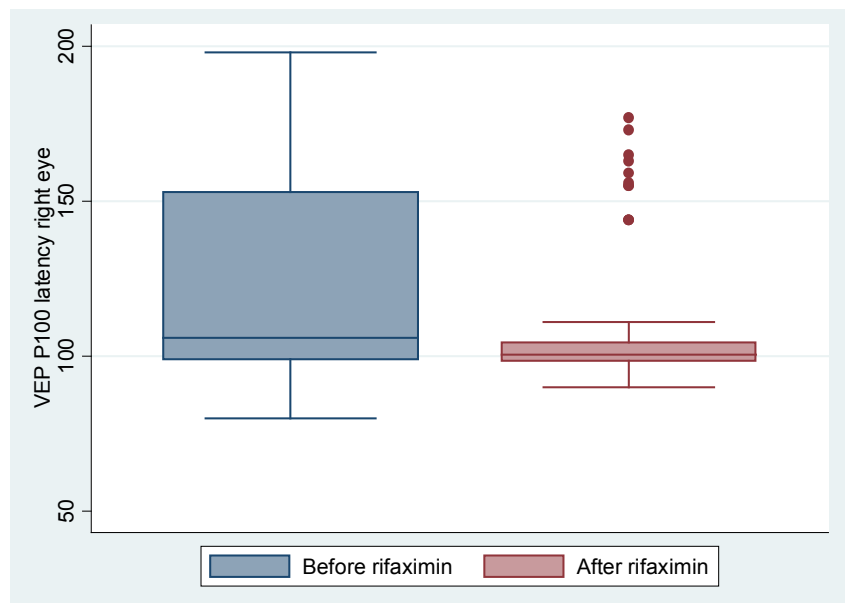

Figure 1. Significant changes in VEP P100 latency right eye before $\&$ after rifaximin. $\mathrm{P}$ value 0.001 .

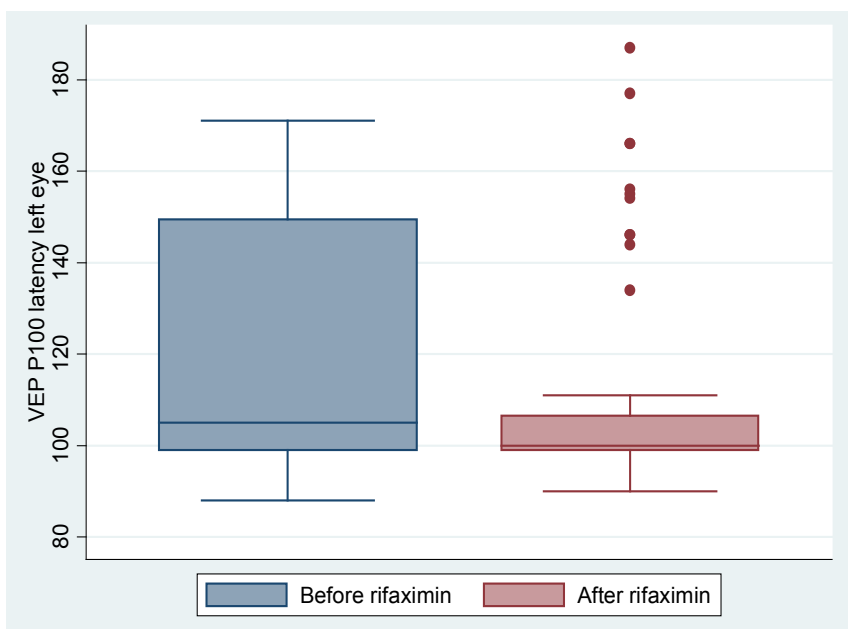

Figure 2. Significant changes in VEP P100 latency left eye before $\&$ after rifaximin. $\mathrm{P}$ value $<0.001$.

\section{Discussion}

MHE impairs patient's daily functioning and quality of life, patients with MHE have difficulties with attention, response inhibition and working memory [28]. 
In our study we diagnosed MHE in 60 cirrhotic patients without overt encephalopathy by using combination of minimental state examination, EEG and VEP P100 event-related potential and this is close to the results of recent reports by Mina et al. [29].

We found that MHE was present in 36\% - 51\% which is close to the esults of previous studies that reported that the prevalence of MHE is high in patients with cirrhosis of liver and varies between $30 \%$ and $84 \%$ [3]. In addition Nardone et al. reported that MHE is the earliest form of hepatic encephalopathy and can affect up to $80 \%$ of patients with liver cirrhosis [30].

Since few studies have examined the applicability of MMSE in screening for liver encephalopathy, it was an important finding in the present study that patients with cirrhosis had a lower performance than controls in the different items of the MMSE and received an average score of $21.3 \pm 3.7$ points on the MMSE, while the control group had an average score of $25.8 \pm 2.9$ points, a finding confirmed by Torres et al. [31] who reported that MMSE could be a useful tool for detecting global cognitive impairment experienced by cirrhotic patients. Being easily applied and widely more studies are needed to determine its sensitivity and specificity of MMSE in screening for minimal hepatic encephalopathy, as this condition is often underdiagnosed.

In our study, Patients with more decompensated liver has lower mean of MMSE than their counterparts $(18.2 \pm 2.2$ versus $22.19 \pm 3.7$ respectively), this may be related to hyperammonemia and this group of patients are more susceptible to HE precipitants [32].

On the contrary, Koziarska et al. [15] who found that MMSE is not useful for diagnosis of MHE and does not correlate with EEG spectral parameters, this may be due to higher prevalence of Child B/C in that study.

Thabut et al. reported that the validated tests (MMSE and Montreal Cognitive Assessment) for the diagnosis of cognitive impairment were superior than psychometric hepatic encephalopathy scor (PHES) in detection of MHE and so PHES require a validation in each country before assessing performances of this score in a pathological setting [17].

EEG has the advantage of detection of covert hepatic encephalopathy and monitoring the severity of $\mathrm{HE}$ regardeless the patient cooperation [33]. Amodio et al. found that in well compensated cirrhotic patients the prognostic value of minor EEG changes might be lower than in patients with advanced liver disease, this was similar to we have found.

This may be due to effect of toxic substances, including ammonia, and of electrolyte imbalances and energy metabolism abnormalities, and EEG and evoked potential alterations are often observed even in MHE in which clinical, overt encephalopathy is not observed [34].

Neurophysiological tools reflect changes in signal transmission, cognitive phenomena and cortical networks oscillatory dynamics wich are altered by H.E. [35] Sandford and Saul found that latency of the P100 wave of VEPs could be used to monitor very mild HE but severe HE couldn't be studied since VEPs re- 
quire patient cooperation In our study VEP had a role in diagnosis of MHE in contrast to Chamuleau et al. [36], Who reported that VEPs had normal values despite significant changes in EEG because the magnocellualar system of the visual pathway, which terminates in the mediotemporal visual associate area (MT area, V5), is more sensitive to blood chemistry changes in the brain related to LC.

Neurophysiological tools are reproducible, relatively easy to perform, noninvasive as compared to the other brain structural or metabolic studies. Also, it is not influenced by learning effects by the patient and it is more sensitive for the diagnosis of MHE than the established psychometric tests.

Inour study VEP had role in diagnosis of MHE in contrast to Chamuleau et al. [36], Who reported that VEPs had normal values despite significant changes in EEG because the magnocellualar system of the visual pathway, which terminates in the mediotemporal visual associate area (MT area, V5), is more sensitive to blood chemistry changes in the brain related to LC.

Our study demonstrates the beneficial effect of rifaximin in patients with cirrhosis who have MHE. Significant changes were observed in EEG and VEP P100 latency after administration of rifaximin.

Ammonia is the most important among various factors implicated in the pathogenesis of OHE/MHE, Several trials using ammonia-lowering therapies such as lactulose/lactitol, probiotics and branched-chain amino acids have shown an improvement in MHE [37]. However, the possible efficacy of a non-absorbable antibiotic such as rifaximin to modulate gut flora and reverse MHE has not been previously studied.

We chose rifaximin which is a gut-selective broad-spectrum antibiotic with minimal systemic absorption as the study drug because it is relatively easily available, well tolerated, and effective in reducing blood ammonia [38].

Shawcross et al. [39] reported that inflammatory markers such as white cell count and C-reactive protein levels were significantly higher in those with MHE than in those without MHE.

Rifaximin has shown a general trend toward better efficacy, better safety, better tolerability than neomycin in patients with Overt hepatic encephalopathy [40].

We observed minor gastrointestinal complaints like that were noted by Jiang et al. [41]. On the other hand, lactulose was associated with many side effects such as flatulence, abdominal discomfort, and diarrhea, which leads to low $(<80 \%)$ adherence [4].

Another attractive option for MHE treatment is probiotics but difficulties in their standardization remain two possible mechanismsby which rifaximin could lead to an improvement in MHE.

First, it could lead to a decrease in serum ammonia concentration by decreasing the ammonia-producing bacteria in the gut, as already shown in a previous study [38]. 
Second, rifaximin could be a key factor in decreasing bacterial translocation and inflammation, thus improving MHE. This hypothesis needs to be studied in future trials.

A second limitation of our study was that follow-up of patients after stopping the treatment was not done. Future prospective trials are required to study the impact of rifaximin treatment on the natural history of MHE, that is, prevention of further episodes of MHE or development of OHE.

We concluded that all patients with cirrhosis, irrespective of their job profile, deserve screening and treatment for MHE to improve their quality of life.

Neurophysiological tests could be used in the diagnosis of this neuropsychiatric syndrome, and the evoked potentials represent a promising tool for the objective diagnosis of minimal hepatic encephalopathy. Rifaximin is a safe and effective treatment for improving cognitive function in patients with MHE.

\section{Conflicts of Interest}

The authors declare no conflicts of interest regarding the publication of this paper.

\section{References}

[1] Ferenci, P., Lockwood, A., Mullen, K., Tarter, R., Weissenborn, K. and Blei, A.T. (2002) Hepatic Encephalopathy_Definition, Nomenclature, Diagnosis, and Quantification: Final Report of the Working Party at the 11th World Congresses of Gastroenterology, Vienna, 1998. Hepatology, 35, 716-721.

https://doi.org/10.1053/jhep.2002.31250

[2] Sarin, S. and Nundy, S. (1985) Subclinical Encephalopathy after Portosystemic Shunts in Patients with Non-Cirrhotic Portal Fibrosis. Liver, 5, 142-146. https://doi.org/10.1111/j.1600-0676.1985.tb00229.x

[3] Dhiman, R.K. and Chawla, Y.K. (2009) Minimal Hepatic Encephalopathy. Indian Journal of Gastroenterology, 28, 5-16. https://doi.org/10.1007/s12664-009-0003-6

[4] Bajaj, J.S., Hafeezullah, M., Hoffmann, R.G. and Saeian, K. (2007) Minimal Hepatic Encephalopathy: A Vehicle for Accidents and Traffic Violations. The American Journal of Gastroenterology, 102, 1903-1909. https://doi.org/10.1111/j.1572-0241.2007.01424.x

[5] Schomerus, H. and Hamster, W. (2001) Quality of Life in Cirrhotics with Minimal Hepatic Encephalopathy. Metabolic Brain Disease, 16, 37-41. https://doi.org/10.1023/A:1011610427843

[6] Bajaj, J.S., Hafeezullah, M., Hoffmann, R.G., Varma, R.R., Franco, J., Binion, D.G., et al. (2007) Navigation Skill Impairment: Another Dimension of the Driving Difficulties in Minimal Hepatic Encephalopathy. Hepatology, 47, 596-604. https://doi.org/10.1002/hep.22032

[7] Sharma, P., Sharma, B.C., Puri, V. and Sarin, S.K. (2008) An Open-Label Randomized Controlled Trial of Lactulose and Probiotics in the Treatment of Minimal Hepatic Encephalopathy. European Journal of Gastroenterology \& Hepatology, 20, 506-511. https://doi.org/10.1097/MEG.0b013e3282f3e6f5

[8] Maclayton, D.O. and Eaton-Maxwell, A. (2009) Rifaximin for Treatment of Hepatic Encephalopathy. Annals of Pharmacotherapy, 43, 77-84. 
https://doi.org/10.1345/aph.1K436

[9] Tarter, R.E., Hegedus, A.M., van Thiel, D.H., Schade, R.R., Gavaler, J.S. and Starzl, T.E. (1984) Nonalcoholic Cirrhosis Associated With Neuropsychological Dysfunction in the Absence of Overt Evidence of Hepatic Encephalopathy. Gastroenterolo$g y, 86,1421-1427$.

[10] Weissenborn, K., Ennen, J.C., Schomerus, H., Rückert, N. and Hecker, H. (2001) Neuropsychological Characterization of Hepatic Encephalopathy. Journal of Hepatology, 34, 768-773. https://doi.org/10.1016/S0168-8278(01)00026-5

[11] Bajaj, J., Cordoba, J., Mullen, K., Amodio, P., Shawcross, D., Butterworth, R., et al. (2011) The Design of Clinical Trials in Hepatic Encephalopathy-An International Society for Hepatic Encephalopathy and Nitrogen Metabolism (ISHEN) Consensus Statement. Alimentary Pharmacology \& Therapeutics, 33, 739-747. https://doi.org/10.1111/j.1365-2036.2011.04590.x

[12] Schiff, S., D’Avanzo, C., Cona, G., Goljahani, A., Montagnese, S., Volpato, C., et al. (2014) Insight into the Relationship between Brain/Behavioral Speed and Variability in Patients with Minimal Hepatic Encephalopathy. Clinical Neurophysiology, 125, 287-297. https://doi.org/10.1016/j.clinph.2013.08.004

[13] Folstein, M.F., Folstein, S.E. and McHugh, P.R. (1975) “Mini-Mental State": A Practical Method for Grading the Cognitive State of Patients for the Clinician. Journal of Psychiatric Research, 12, 189-198. https://doi.org/10.1016/0022-3956(75)90026-6

[14] Montagnese, S., Gordon, H.M., Jackson, C., Smith, J., Tognella, P., Jethwa, N., et al. (2005) Disruption of Smooth Pursuit Eye Movements in Cirrhosis: Relationship to Hepatic Encephalopathy and Its Treatment. Hepatology, 42, 772-781. https://doi.org/10.1002/hep.20855

[15] Koziarska, D., Wunsch, E., Milkiewicz, M., Wójcicki, M., Nowacki, P. and Milkiewicz, P. (2013) Mini-Mental State Examination in Patients with Hepatic Encephalopathy and Liver Cirrhosis: A Prospective, Quantified Electroencephalography Study. BMC Gastroenterology, 13, 107. https://doi.org/10.1186/1471-230X-13-107

[16] Conn, H., Leevy, C., Vlahcevic, Z., Rodgers, J., Maddrey, W., Seeff, L., et al. (1977) Comparison of Lactulose and Neomycin in the Treatment of Chronic Portal-Systemic Encephalopathy: A Double Blind Controlled Trial. Gastroenterology, 72, 573-783.

[17] Thabut, D., Kinugawa, K. and Weiss, N. (2014) Diagnosis of Minimal Hepatic Encephalopathy in Patients with Cirrhosis: Should We Bury Psychometric Tests? $\mathrm{He}$ patology, 59, 2428.https://doi.org/10.1002/hep.26967

[18] Amodio, P. and Montagnese, S. (2015) Clinical Neurophysiology of Hepatic Encephalopathy. Journal of Clinical \& Experimental Hepatology, 5, S60-S68. https://doi.org/10.1016/j.jceh.2014.06.007

[19] Pugh, R., Murray-Lyon, I., Dawson, J., Pietroni, M. and Williams, R. (1973) Transection of the Oesophagus for Bleeding Oesophageal Varices. British Journal of Surgery, 60, 646-649. https://doi.org/10.1002/bjs.1800600817

[20] Mungas, D. (1991) Iii-Office Mental Status Testing: A Practical Guide. Geriatrics, 46, 54-67.

[21] Kochhann, R., Cerveira, M.O., Godinho, C., Camozzato, A. and Chaves, M.L.F. (2009) Evaluation of Mini-Mental State Examination Scores According to Different Age and Education Strata, and Sex, in a Large Brazilian Healthy Sample. Dementia \& Neuropsychologia, 3, 88-93. https://doi.org/10.1590/S1980-57642009DN30200004

[22] Lourenço, R.A. and Veras, R.P. (2006) Mini-Mental State Examination: Psychome- 
tric Characteristics in Elderly Outpatients. Revista de Saúde Pública, 40, 712-719. https://doi.org/10.1590/S0034-89102006000500023

[23] Kochhann, R., Varela, J.S., de Macedo Lisboa, C.S. and Chaves, M.L.F. (2010) The Mini Mental State Examination: Review of Cutoff Points Adjusted for Schooling in a Large Southern Brazilian Sample. Dementia \& Neuropsychologia, 4, 35-41. https://doi.org/10.1590/S1980-57642010DN40100006

[24] Parsons-Smith, B., Summerskill, W., Dawson, A. and Sherlock, S. (1957) The Electroencephalograph in Liver Disease. The Lancet, 270, 867-871. https://doi.org/10.1016/S0140-6736(57)90005-3

[25] Child, C. and Turcotte, J. (1964) Surgery in Portal Hypertension. Major Problems in Clinical Surgery: The Liver and Portal Hypertension. Saunders, Philadelphia.

[26] Epstein, C. (2006) American Clinical Neurophysiology Society Guideline 5: Guidelines for Standard Electrode Position Nomenclature. Journal of Clinical Neurophysiology, 23, 107-110. https://doi.org/10.1097/00004691-200604000-00006

[27] Tandon, O. and Sharma, K. (1989) Visual Evoked Potential in Young Adults: A Normative Study. Indian Journal of Physiology and Pharmacology, 33, 247-249.

[28] Weissenborn, K., Giewekemeyer, K., Heidenreich, S., Bokemeyer, M., Berding, G. and Ahl, B. (2005) Attention, Memory, and Cognitive Function in Hepatic Encephalopathy. Metabolic Brain Disease, 20, 359-367. https://doi.org/10.1007/s11011-005-7919-Z

[29] Mina, A., Moran, S., Ortiz-Olvera, N., Mera, R. and Uribe, M. (2014) Prevalence of Minimal Hepatic Encephalopathy and Quality of Life in Patients with Decompensated Cirrhosis. Hepatology Research, 44, E92-E99. https://doi.org/10.1111/hepr.12227

[30] Nardone, R., Taylor, A.C., Höller, Y., Brigo, F., Lochner, P. and Trinka, E. (2016) Minimal Hepatic Encephalopathy: A Review. Neuroscience Research, 111, 1-12. https://doi.org/10.1016/j.neures.2016.04.009

[31] Torres, D., Abrantes, J. and Brandão-Mello, C. (2013) Cognitive Assessment of Patients with Minimal Hepatic Encephalopathy in Brazil. Metabolic Brain Disease, 28, 473-483. https://doi.org/10.1007/s11011-013-9405-3

[32] Montagnese, S., Biancardi, A., Schiff, S., Carraro, P., Carla, V., Mannaioni, G., et al. (2011) Different Biochemical Correlates for Different Neuropsychiatric Abnormalities in Patients with Cirrhosis. Hepatology, 53, 558-566.

https://doi.org/10.1002/hep.24043

[33] Amodio, P., Del Piccolo, F., Pettenò, E., Mapelli, D., Angeli, P., Iemmolo, R., et al. (2001) Prevalence and Prognostic Value of Quantified Electroencephalogram (EEG) Alterations in Cirrhotic Patients. Journal of Hepatology, 35, 37-45. https://doi.org/10.1016/S0168-8278(01)00129-5

[34] Caspers, H. (1983) Electroencephalography: Basic Principles, Clinical Applications and Related Fields. Ernst Niedermeyer, Fernando Lopes da Silva. The Quarterly Review of Biology, 58, 301-302. https://doi.org/10.1086/413356

[35] Sandford, N.L. and Saul, R.E. (1988) Assessment of Hepatic Encephalopathy with Visual Evoked Potentials Compared with Conventional Methods. Hepatology, 8, 1094-1098. https://doi.org/10.1002/hep.1840080519

[36] Chamuleau, R., Deutz, N., De Haan, J. and Van Gool, J. (1987) Correlation between Electroencephalographic and Biochemical Indices in Acute Hepatic Encephalopathy in Rats. Journal of Hepatology, 4, 299-306. https://doi.org/10.1016/S0168-8278(87)80538-X 
[37] Egberts, E., Schomerus, H., Hamster, W. and Jürgens, P. (1985) Branched Chain Amino Acids in the Treatment of Latent Portosystemic Encephalopathy: A DoubleBlind Placebo-Controlled Crossover Study. Gastroenterology, 88, 887-895. https://doi.org/10.1016/S0016-5085(85)80004-4

[38] Pedretti, G., Calzetti, C., Missale, G. and Fiaccadori, F. (1991) Rifaximin versus Neomycin on Hyperammoniemia in Chronic Portal Systemic Encephalopathy of Cirrhotics. A Double-Blind, Randomized Trial. The Italian Journal of Gastroenterology, 23, 175-178.

[39] Shawcross, D.L., Davies, N.A., Williams, R. and Jalan, R. (2004) Systemic Inflammatory Response Exacerbates the Neuropsychological Effects of Induced Hyperammonemia in Cirrhosis. Journal of Hepatology, 40, 247-254. https://doi.org/10.1016/j.jhep.2003.10.016

[40] Leevy, C.B. and Phillips, J.A. (2007) Hospitalizations during the Use of Rifaximin versus Lactulose for the Treatment of Hepatic Encephalopathy. Digestive Diseases and Sciences, 52, 737-741. https://doi.org/10.1007/s10620-006-9442-4

[41] Jiang, Q., Jiang, X.-H., Zheng, M.-H., Jiang, L.-M., Chen, Y.-P. and Wang, L. (2008) Rifaximin versus Nonabsorbable Disaccharides in the Management of Hepatic Encephalopathy: A Meta-Analysis. European Journal of Gastroenterology \& Hepatology, 20, 1064-1070. https://doi.org/10.1097/MEG.0b013e328302f470 